\title{
Design and experiment of a high-clearance self-propelled sprayer chassis
}

\author{
Yu Chen ${ }^{1}$, Enrong Mao ${ }^{2}$, Wei Li ${ }^{2}$, Shuo Zhang ${ }^{1}$, Zhenghe Song ${ }^{2}$, Shanju Yang ${ }^{1}$, Jun Chen ${ }^{1 *}$ \\ (1. College of Mechanical and Electronic Engineering, Northwest A\&F University, Yangling 712100, China; \\ 2. College of Engineering, China Agricultural University, Beijing 100083, China)
}

\begin{abstract}
A large high-clearance self-propelled sprayer chassis was designed according to the requirements of the sprayer's driving operation and the overall goal. The structural characteristics and working principle of the chassis drive system, suspension system, track adjustment system, and frame were analyzed. A finite element analysis of the frame was carried out under four extreme conditions: full load bending, full load torsion, full load emergency braking and full load emergency turning. Under these four conditions, the maximum stress values of the frame were $149.45 \mathrm{MPa}, 219 \mathrm{MPa}, 151.44 \mathrm{MPa}$, and 123.27 MPa respectively, and the maximum strain values were $1.12 \mathrm{~mm}, 2.22 \mathrm{~mm}, 0.95 \mathrm{~mm}$, and $1.16 \mathrm{~mm}$ respectively. A theoretical analysis of the stability, steering ability, and obstacle navigation of the sprayer chassis was conducted. The results showed that the upper angle $\theta_{\lim }$, lower angle $\theta_{\text {lim }}^{\prime}$ and lateral limit tumbling angle $\varphi_{\text {lim }}$ of the sprayer chassis were $50.1^{\circ}, 30.0^{\circ}$ and $35.3^{\circ}$ respectively. The minimum turning radius of the chassis was $5816 \mathrm{~mm}$, and the minimum turning width was $4113 \mathrm{~mm}$. The maximum obstacle crossing heights of the front and rear wheels were $466 \mathrm{~mm}$ and $457 \mathrm{~mm}$. The theoretical analysis showed that the designed chassis met the field management operations of large plots. A field experiment of the high-clearance self-propelled sprayer chassis at full load was conducted. The experimental results were consistent with the theoretical analysis results. The sprayer chassis not only good handling stability but also good ride comfort. The results of this study provide references for the design of high-clearance self-propelled sprayer chassis
\end{abstract}

Keywords: high-clearance self-propelled sprayer, chassis performance, frame, suspension, design, experiment

DOI: $10.25165 /$ j.ijabe.20201302.5262

Citation: Chen Y, Mao E R, Li W, Zhang S, Song Z H, Yang S J, et al. Design and experiment of a high-clearance self-propelled sprayer chassis. Int J Agric \& Biol Eng, 2020; 13(2): 71-80.

\section{Introduction}

As the main method to prevent and eliminate crop diseases and insect pests, pesticide applications have become an important measure to improve crop yield ${ }^{[1]}$. With the advancement of agricultural mechanization and the implementation of large-scale farm cooperative management approaches, high-clearance and high-efficiency field management machinery is needed to address the spraying and fertilizing requirements of tall crops. A high-clearance self-propelled sprayer is an important machine for spraying and fertilizing tall crops ${ }^{[2,3]}$. Self-propelled sprayers have been developed for decades and their work efficiency and intelligence are constantly increasing ${ }^{[4,5]}$.

The sprayer operating conditions are complex. To ensure an efficiency operation of the sprayer and optimum spray quality, scholars have carried out a lot of research on its spray system and

\section{Received date: 2019-07-03 Accepted date: 2020-01-15}

Biographies: Yu Chen, $\mathrm{PhD}$, Lecturer, research interests: design, analysis and control of large agricultural machinery, Email: jdxy73@nwafu.edu.cn; Enrong Mao, PhD, Professor, research interests: vehicle ergonomics, system dynamics and intelligent technology, Email: gxy15@cau.edu.cn; Wei Li, PhD candidate, research interests: vehicle electronic control and intelligent technology, Email: 13031131055@163.com; Shuo Zhang, PhD, Lecturer, research interests: control of intelligent agricultural equipment, Email: zhangshuo@nwafu.edu.cn; Zhenghe Song, $\mathrm{PhD}$, Professor, research interests: vehicle ergonomics and intelligent control , Email: gxy16@cau.edu.cn; Shanju Yang, PhD, Lecturer, research interests: high-speed rotating machinery and fluid lubrication technology, Email: yangshanju@nwafu.edu.

*Corresponding author: Jun Chen, $\mathrm{PhD}$, Professor, research interests: intelligent agricultural equipment technology and vehicle performance testing. Mailing address: College of Mechanical and Electronic Engineering, Northwest A\&F University, Yangling 712100, China. Tel: +86-29-87091867, Email: chenjun_jdxy@nwafu.edu.cn. boom system ${ }^{[6,7]}$. Cui et al. ${ }^{[8,9]}$ established a mathematical model of active spray boom suspension on the basis of analyzing the dynamic characteristics of passive suspension. The effects of control system parameters on the response characteristics and tracking errors of the boom were revealed through simulation and experiments. The research results provide a theoretical basis for parameter optimization of large boom suspensions. Thmasebi et al. ${ }^{[10,11]}$ proposed an active control method for boom suspension, and applied a neural network-based proportional-integral-derivative (PID) algorithm to control the boom suspension. The experimental results showed that the method significantly suppressed the boom vibration. In addition, Xue et al. ${ }^{[12]}$, Parloo et al. ${ }^{[13,14]}$, and Wei et al. ${ }^{[15]}$ investigated the design and control of sprayer booms, which solved the problem of sprayer booms vibration caused by ground excitation.

These studies, however, mainly focus on the characteristics analysis and control methods of sprayer boom suspension ${ }^{[16,17]}$. The chassis ${ }^{[18]}$ is the basis of a self-propelled sprayer. The drive system $^{[19,20]}$, frame ${ }^{[21,22]}$, steering system ${ }^{[23,24]}$, and suspension system $^{[25,26]}$ of the chassis affect the sprayer's ride comfort, handling stability, flexibility, passability and safety ${ }^{[27,28]}$. The importance of the chassis to the self-propelled sprayer has been increasingly valued by researchers. For example, to achieve good ride comfort of the sprayer chassis, air springs, hydro-pneumatic springs, and radial tires have been widely used in sprayers ${ }^{[29-32]}$. John Deere, AGCO and other companies' sprayers have been equipped with air suspension or hydro-pneumatic suspension and body leveling systems, which can effectively cushion the impact of uneven ground.

In this study, a high-clearance self-propelled sprayer chassis was designed with the overall goal of meeting the management requirements of field crops and specifically considering factors 
such as sprayer handling stability, ride comfort, work efficiency, and suitability. The chassis performance, such as the handling stability, steering ability, and obstacle crossing were analyzed. A high-clearance self-propelled sprayer chassis test platform was built and a chassis experiment was carried out. The results of this study provide references for the design of self-propelled sprayer chassis.

\section{Overall design aspects}

\subsection{Overall objective}

A large high-clearance self-propelled sprayer chassis test platform was designed and built. The overall design objectives for the chassis are as follows:

(1) In order to meet the needs of plant protection of most crops, the ground clearance of the chassis needs to be at least $2000 \mathrm{~mm}$;

(2) The chassis should have a wide range of driving speeds $(1-40 \mathrm{~km} / \mathrm{h})$ that are adjustable in four steps to ensure that the sprayer is adaptable to the speed requirements of different working conditions such as plant protection and road transportation.

(3) The chassis should have the characteristics of a small turning radius and flexible steering. Field research and experiments have shown that the turning radius should be no more than $6500 \mathrm{~mm}$ for four-wheel steering.

(4) In order to meet the needs of plant protection of different crops, the chassis needs to be equipped with a hydraulic wheel track adjustment device with an adjustment range of 3200-4000 $\mathrm{mm}$.

(5) The chassis should be equipped with an independent strut-type suspension system with a large vibration reduction range $( \pm 100 \mathrm{~mm})$ and high ground clearance to ensure good ride comfort when the chassis is driven on uneven roads.

\subsection{Structure and working principle of the machine}

As shown in Figure 1, the large high-clearance self-propelled sprayer designed in this study consists of a cab (2), an engine (7), a hydraulic oil tank (11), front and rear suspensions $(3,9)$ (the suspension consists of a guide column (4), air reservoir (14), spring height sensor (15), air spring (16), vertical shaft (19), etc.), wheel track adjustment cylinders $(20,21)$, a frame (23), a hydraulic line (24), front and rear wheels $(22,27)$, and other related components.

In addition to the high-stalk crop planting mode and agronomic demand, the main structural parameters such as ground clearance, wheel track, and the wheelbase of the chassis are determined to maximize the adaptability of the sprayer and reduce the damage of the mechanical structure to the crop during operations.

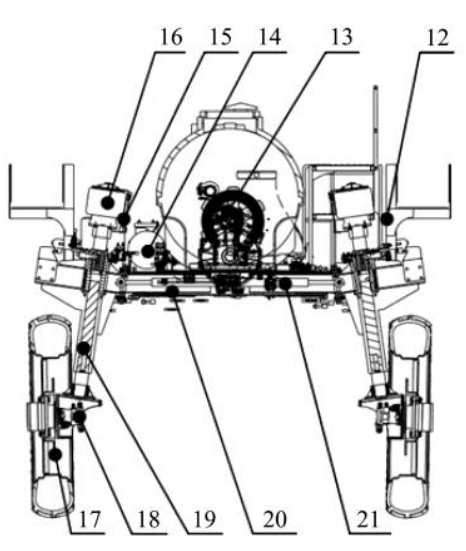

a. Cutaway view of A-A

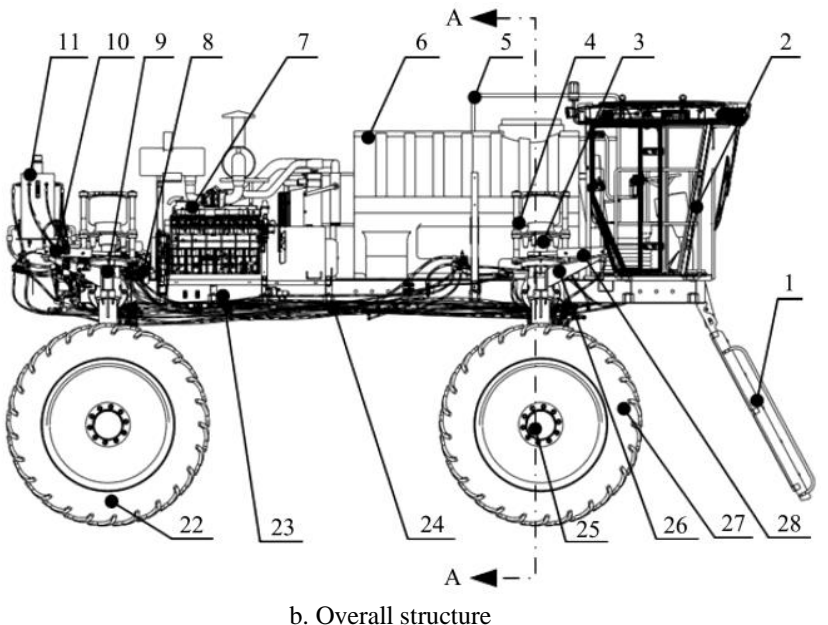

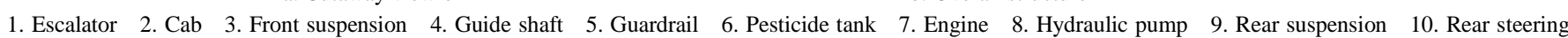
hydraulic cylinder 11. Hydraulic oil tank 12. Spray rod placement frame 13. Radiator 14 . Air reservoir 15. Air spring height sensor 16. Air spring 17. Brake disc 18. Hydraulic motor 19. Vertical shaft 20. Left front wheel track adjustment cylinder 21. Right front wheel track adjustment cylinder 22. Rear travel wheel

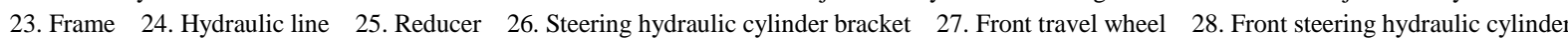

Figure 1 Large-scale high-clearance self-propelled sprayer chassis

In order to meet the requirements of high-speed transportation, plant protection, high ground clearance, large vibration reduction stroke, and flexible steering, the sprayer chassis is equipped with four independent strut-type air suspensions and each suspension is integrated with a hydraulic steering device. In order to reduce the crushing and destruction of crops and soil by the machine and improve the travel path of the machine, vacuum meridian cultivating tires are used with a cross-sectional width of $380 \mathrm{~mm}$ and a diameter of $1852 \mathrm{~mm}$; these tires have a large diameter, narrow tread, low air pressure, large surface contact, and high carrying capacity. The pesticide tank is made of PE material with good heat resistance and corrosion resistance. The overall length, width, and height of the pesticide tank are $2080 \mathrm{~mm}, 1400 \mathrm{~mm}$, and $1500 \mathrm{~mm}$, and the volume is $3000 \mathrm{~L}$. The internal cavity of the pesticide tank is approximately cylindrical, and the length and diameter of the cylinder are $2000 \mathrm{~mm}$ and $1382 \mathrm{~mm}$, respectively. The main technical data of the designed sprayer are shown in Table 1.
Table 1 Principal technical data of sprayer overall design

\begin{tabular}{lc}
\hline \multicolumn{1}{c}{ Parameter } & Index \\
\hline Drive mode & Four-wheel hydrostatic drive \\
Engine horsepower/hp & 205 \\
Full load/kg & 12000 \\
Boundary dimension/mm & $7500 \times 4500 \times 4500$ \\
Volume of pesticide tank/L & 3000 \\
Speed/km/ ${ }^{-1}$ & Four-speed stepless speed change, \\
& the highest: $17 ; 23 ; 26 ; 40$ \\
Damping range/mm & \pm 100 \\
Minimum turning radius/mm & $\leq 6500$ \\
Wheel track/mm & $3200-4000$ \\
Wheelbase/mm & 4000 \\
Clearance/mm & $\geq 2000$ \\
Service brake & Clamp plate hydraulic brake \\
Parking brake & Multi-disc brake in the reducer \\
\hline
\end{tabular}




\section{Methods}

\subsection{Design of the running and driving system}

\subsubsection{Design of driving system}

Due to the advantages of the hydrostatic driving mode and the overall design requirements of the sprayer, an " $X$ "-type hydrostatic wheel drive system consisting of two closed swashplate axial piston variable pumps, four plunger motors, and four reducers was selected to achieve the high-speed and high-efficiency driving requirements of the large high-clearance self-propelled sprayer. The sprayer drive scheme is shown in Figure 2.

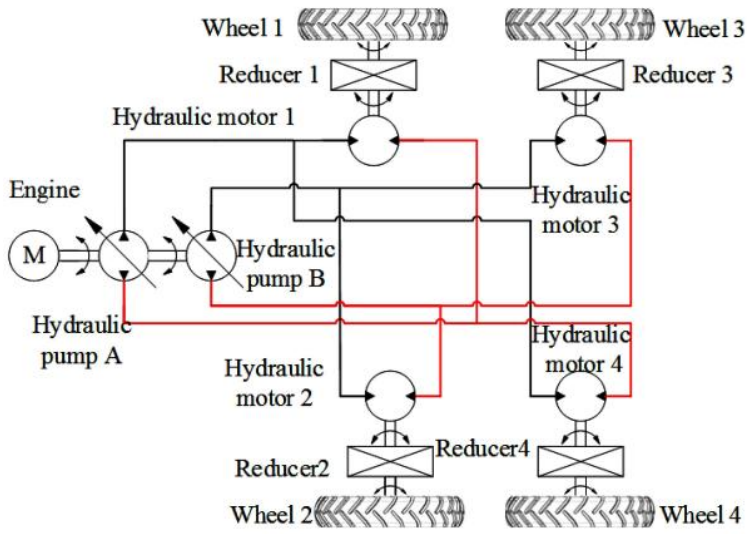

Figure 2 Sprayer hydrostatic drive scheme

The engine power is distributed to pump A and pump B; pump A drives the motors 1 and 4 and pump B drives the motors 2 and 3 . Each motor drives a reducer and a wheel. The advantages of the "X" drive scheme are as follows. If the road traction of wheel 1 deteriorates, the traction force of wheel 1 decreases. Since wheel 4 and wheel 1 are connected in parallel by the hydraulic pump A, the traction force of wheel 4 is also reduced. However, wheel 2 and wheel 3, which are driven by hydraulic pump B still maintain a large traction force, thereby ensuring the traction performance of the machine and keeping the slip rate of all wheels within the allowable ranges.

\subsubsection{Design of the suspension system}

An independent strut-type active air suspension system suitable for large sprayers was designed. As shown in Figure 3, parts 1-2, 9-10, and 15-17 comprise the tire assembly T. Parts 7, 8 , and 13 comprise the steering assembly $\mathbf{Z}$. Parts 5-6, 11-12, $18-23$, and 14 comprise the suspension assembly S. Vacuum meridian cultivating tires produced by BKT of India were used and the tire model was 380/90R46. The elastic elements of the suspension were Firestone's 1T19L-7 air springs. The spring damping range was about $\pm 100 \mathrm{~mm}$ based on the action of the spring's internal buffer block and limiting block 20. A spring height control valve 21 was used to control the spring's inflation and deflation. The suspension system functions were as follows:

(1) The upper and lower sides of the vertical shaft 11 were connected to $\mathbf{T}$ and $\mathbf{S}$, respectively, to support and transmit the vibration. During the suspension vibration reduction process, the vibration transmission route was $1 \rightarrow 10 \rightarrow 11 \rightarrow 14 \rightarrow 6 \rightarrow 5 \rightarrow 18 \rightarrow 13$ $\rightarrow 3$.

(2) The two ends of the steering cylinder 7 were respectively connected to the steering arm welding joint 13 and the steering cylinder support arm welding joint 8 . The steering cylinder was extended and shortened to drive the wheel deflection for steering. Due to the limiting action of the positioning ring 12 , the steering arm welding joint 13 could only rotate relative to the beam support column 3 and could not move axially relative to the beam support column 3. During steering, the torque transmission route was $7 \rightarrow 13 \rightarrow 18 \rightarrow 5 \rightarrow 6 \rightarrow 14 \rightarrow 11 \rightarrow 10 \rightarrow 1$.

(3) During the wheel track adjustment process, the suspension assembly was moved by the wheel track adjustment cylinder installed at 4 and the motion transmission route was $4 \rightarrow 3 \rightarrow 11 \rightarrow 10 \rightarrow 1$.

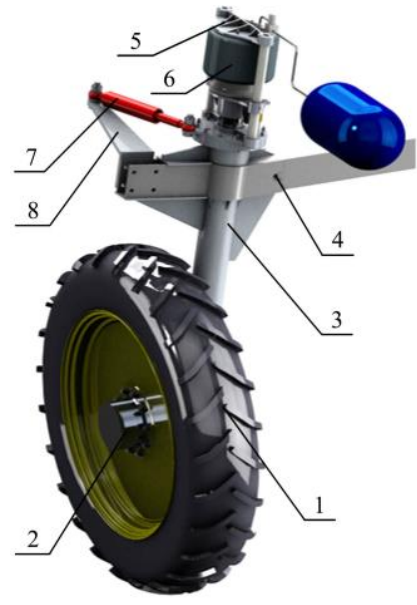

a. Exterior view

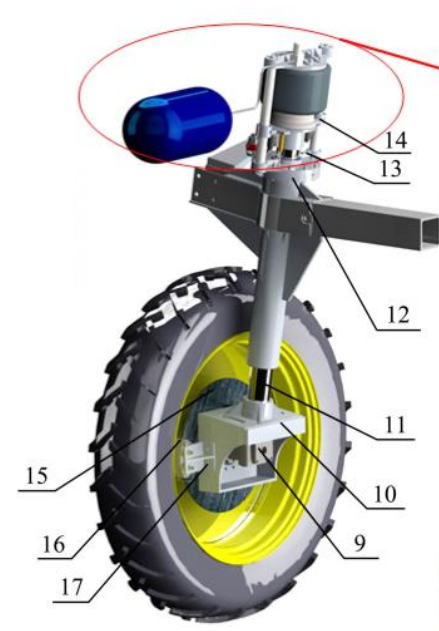

b. Inner view

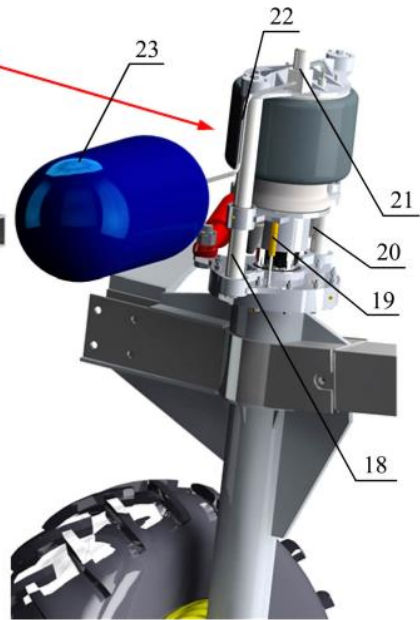

c. Partial magnification

1. Wheel 2. Reducer 3. Beam support column welding 4. Track adjustment cylinder mounting hole 5. Spring top support welding 6. Air spring 7. Steering cylinder 8. Steering cylinder support arm welding 9. Hydraulic motor 10 . Motor protection housing welding 11. Vertical shaft 12. Positioning ring 13. Steering arm welding 14. Spring bottom support welding 15. Brake disc 16. Brake caliper 17. Brake caliper installation welding 18. Guide post 19. Height sensor 20. Rubber limit block 21. Height control valve 22. Compressed air hose 23. Air reservoir

Figure 3 Instruction diagram of sprayer chassis suspension

\subsubsection{Design of the wheel track adjustment system}

The wheel track adjustment system is the key device to improve the adaptability of the sprayer to different crops and plots. Combined with the structural characteristics of the independent strut-type air suspension, a hydraulic wheel track adjustment device was designed, as shown in Figure 4 . The track adjustment cylinder was arranged on the inner side of the frame axle housing and the inlet and outlet oil pipes of the cylinder were connected to the outside through small holes of the window covers 2 and 5 . The positioning sleeve 4 allowed the cylinder 6 to always be in the middle position in the frame axle housing. When the track was adjusted, the suspension beam (Figure 3) was sliding relative to the 
copper base track adjustment bearing 3 in the frame axle housing (Figure 4).

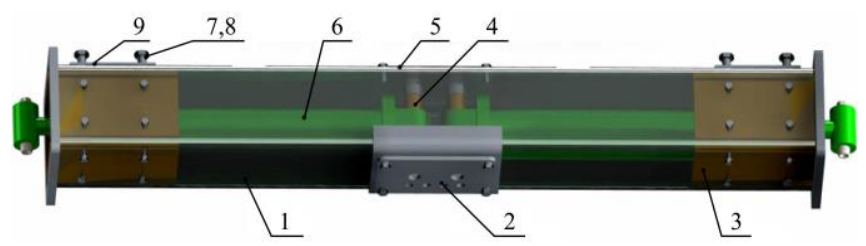

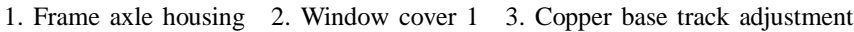
sliding bearing 4. Cylinder positioning sleeve 5. Window cover 26 . Track adjustment cylinder 7. Clearance adjustment bolt 8 . Lock nut 9. Bridge shell reinforcement

Figure 4 Structure of hydraulic wheel track adjustment device

Due to machining error and reserved assembly clearance, a perfect fit could not be achieved for the suspension beam and the copper base track adjustment bearing, as shown in Figure 5a. In order to ensure uniform contact between the suspension beam and the copper base track adjustment bearing and ensure that the suspension beam did not sway in the frame axle housing, clearance adjustment bolts and lock nuts were used to eliminate the clearance, as shown in Figure 5b.

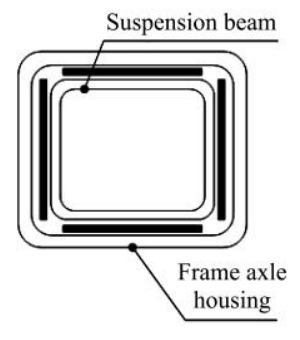

a.

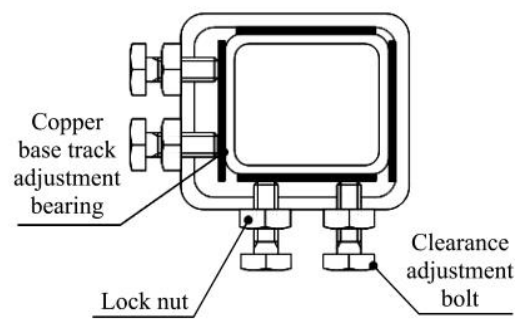

b.
Figure 5 Assembly relationship between suspension beam and frame axle housing

\subsection{Design of the frame}

\subsubsection{Structural design of the frame}

The frame is one of the key components of the sprayer and affects the sprayer's stability and service life. The frame is subject to a variety of large bending moments and torques during spraying and transferring operations. The side beam frame had the advantages of being able to withstand bending and torque well under extreme conditions and it was easy to install by using various work attachments. The frame designed in this study combined the characteristics of the side beam frame and was equipped with an $\mathrm{X}$-shaped reinforcing beam, which provided the frame with higher rigidity and better torsion resistance. As shown in Figure 6, the large sprayer frame consisted of a front cross member (1), two front longitudinal beams (2), a front axle (4), two reinforcing beams (6), an intermediate beam (8), two longitudinal beams (9), a rear axle (12), other supports, and connecting plates. The front cross-member (1) and intermediate cross member (8) were rectangular tubes with dimensions of $100 \mathrm{~mm} \times 180 \mathrm{~mm} \times 9 \mathrm{~mm}$. The front axle (4) and rear axle (12) were square tubes with a cross-section of $220 \mathrm{~mm} \times 10 \mathrm{~mm}$. The reinforcing beams (6) were made of grooved steel with a section of $180 \mathrm{~mm} \times 70 \mathrm{~mm} \times$ $10 \mathrm{~mm}$. The front longitudinal beams (2) and the other longitudinal beams (9) consisted of several layers, i.e., the layered longitudinal beam consisted of several spliced two-groove beams. The layered stringers had the same torsional and bending resistance as the closed section, which met the requirements of the sprayer frame for stiffness and strength. Considering material cost and processing technology factors, Q345B was selected for the frame material.

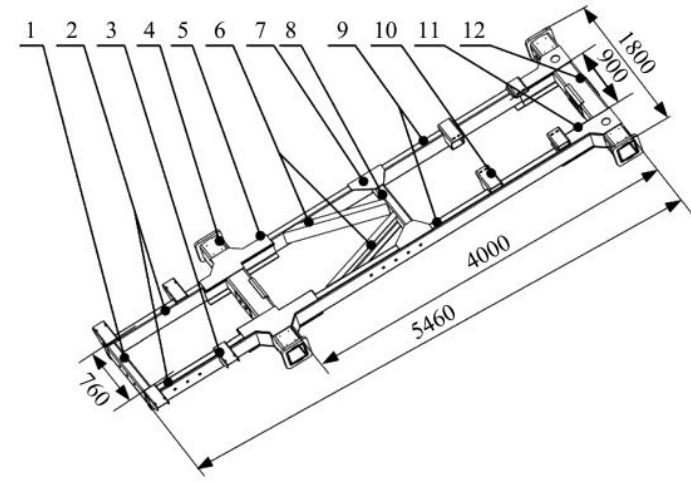

1. Front cross member 2. Front longitudinal beam 3. Cab mount 4. Front axle 5. Front connecting plate 6. Reinforcing beam 7. Intermediate connecting plate 8 . Intermediate beam 9. Longitudinal beam 10. Engine mount 11. Rear connection plate 12. Rear axle

Figure 6 Overall structure of sprayer chassis frame

\subsubsection{Finite element analysis of the frame}

The frame 3D model created by Creo was imported into ANSYS Workbench, and the stiffness and strength analysis of the frame was performed. In order to improve the simulation speed and accuracy, the bosses, chamfers, small holes, etc. of the frame model were simplified, and the influence of the welding process on the structural characteristics of the frame material was ignored. The frame material had an elastic modulus of $206 \mathrm{GPa}$, a Poisson's ratio of 0.28 , a yield strength of $345 \mathrm{MPa}$, and a density of $7.85 \mathrm{~kg} / \mathrm{mm}^{3}$. ANSYS MESH module was applied to mesh the frame. According to the actual position of the cab, fully loaded medicine tank, engine, boom, fuel tank, etc., load force was applied to the frame. In order to analyze the stress and strain of the sprayer frame under four typical conditions of bending, torsion, emergency braking and emergency turning, the full-load bending load factor, full-load torsion load factor, full-load emergency braking load factor, and full-load emergency cornering load factor were selected to be $2.5,1.3,2.0$, and 2.0, respectively. Among them, the full load bending condition refers to the condition that the boom is deployed when the sprayer is fully loaded. Full-load torsion condition refers to the state when the sprayer is fully loaded and a certain wheel is suspended causing the frame to twist.

The deformation distribution of the frame in full load bending condition was shown in Figure $7 \mathrm{a}$. The frame maximum deformation was in the middle of the frame, the connection between the medicine box and the engine installation, and the front of the frame. The maximum deformation was $1.12 \mathrm{~mm}$. The equivalent stress in full load bending condition was shown in Figure 7b. The overall bending stress of the frame was below $56 \mathrm{MPa}$, which was far less than the material's ultimate yield strength of $345 \mathrm{MPa}$, and less than the allowable stress of $138 \mathrm{MPa}$ $(345 / 2.5)$. The calculated maximum stress value in Figure $7 \mathrm{~b}$ was 149.45 MPa, which appeared at the contact between the upper surface of the rear axle interior and the track-adjusting rectangular beam. Because the rounded corners of the rectangular rear bridge were simplified to right angles during the analysis, stress concentration occurred.

When the left front wheel of the sprayer was suspended, the deformation distribution of the frame in full load torsion condition was shown in Figure 7c. The maximum deformation of the frame was $2.22 \mathrm{~mm}$. According to similar mechanical standards, this deformation value was small. The stress distribution of the frame in full load torsion condition was shown in Figure $7 \mathrm{~d}$. The maximum stress point was at the edge where the front axle housing contacted the track-adjusting rectangular beam, which was 
$219 \mathrm{MPa}$. The overall frame stress was below $90 \mathrm{MPa}$, which was far less than the allowable stress of $265 \mathrm{MPa}$.

When the maximum adhesion coefficient was set to 0.7 , the maximum deformation of the frame in full load emergency braking condition was $0.95 \mathrm{~mm}$, and the maximum stress value was 151.44 MPa, as shown in Figures 7e and 7f. The maximum stress value was less than the allowable stress value of 172.5 MPa. Taking a left turn as an example, the maximum deformation of the

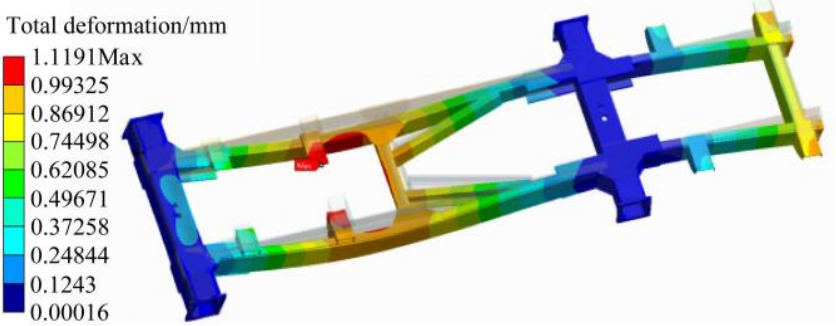

a. Distribution of deformation in full load bending

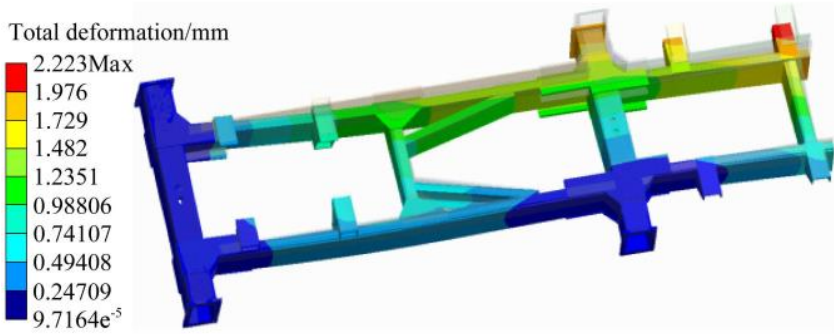

c. Distribution of deformation in full load torsion

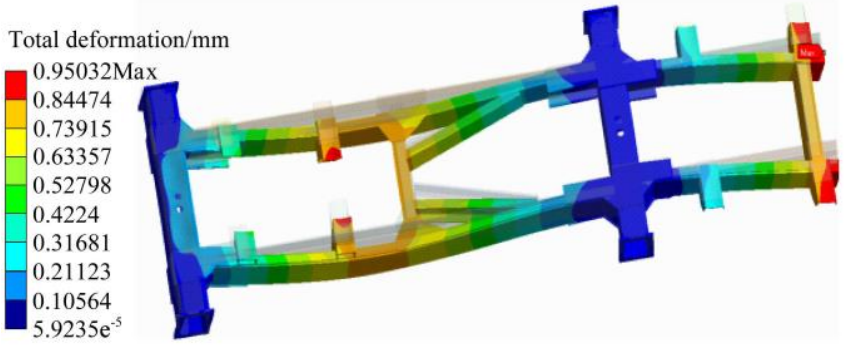

e. Distribution of deformation in load emergency braking

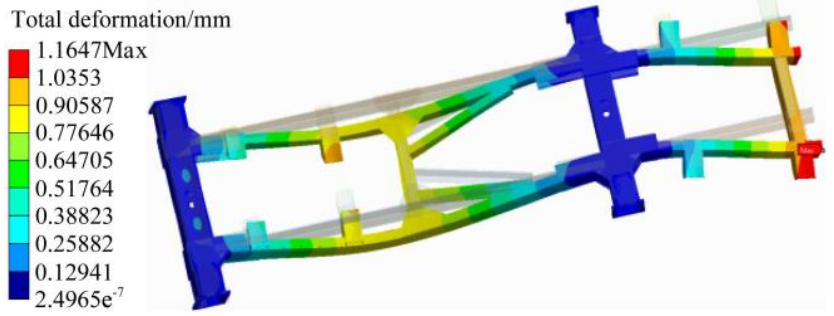

g. Distribution of deformation in full load emergency turn frame in full load emergency turning condition was $1.16 \mathrm{~mm}$, and the maximum stress value was $123.27 \mathrm{MPa}$, as shown in Figures $7 \mathrm{~g}$ and $7 \mathrm{~h}$. The maximum stress value was less than the allowable stress value of $172.5 \mathrm{MPa}$. According to the results of static analysis of various working conditions, the overall stiffness and strength of the frame are good. The analysis results provide guidance for further dynamic analysis, frame structure and size optimization.

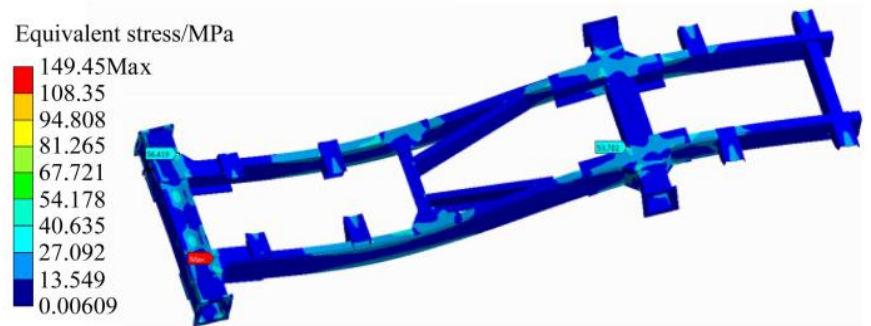

b. Equivalent stress distribution in full load bending

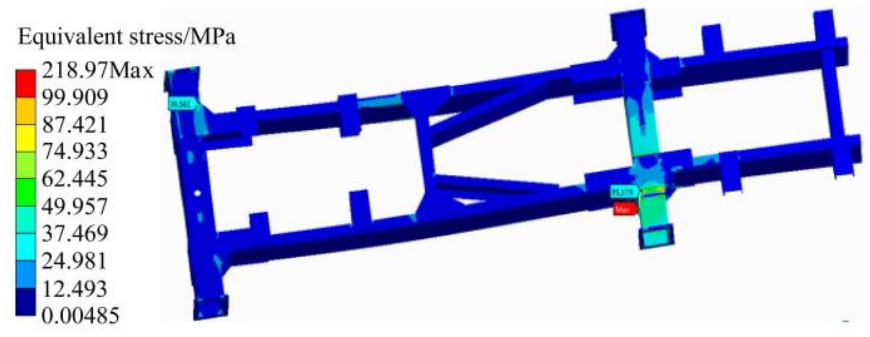

d. Equivalent stress distribution in full load torsion

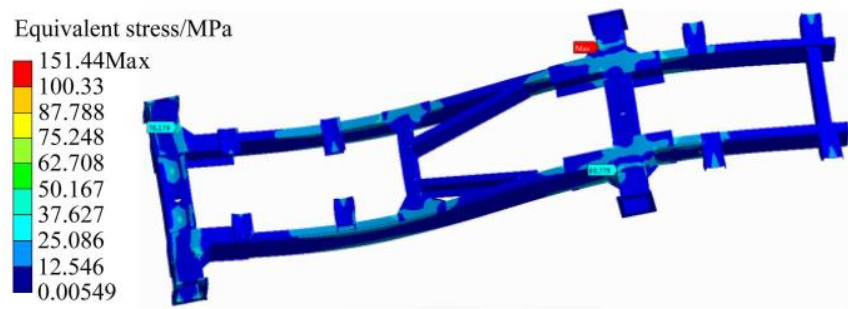

f. Equivalent stress distribution in load emergency braking

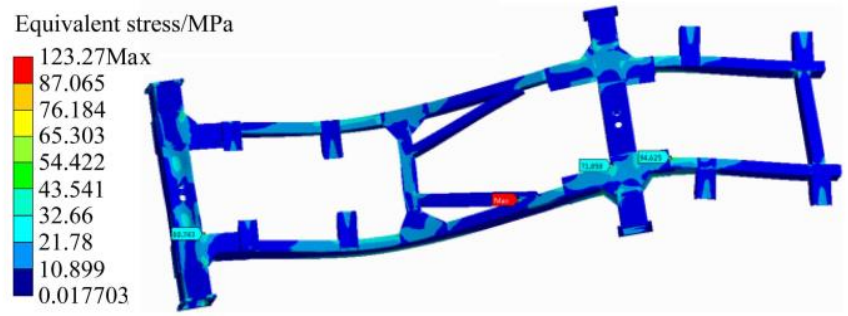

h. Equivalent stress distribution in full load emergency turn

Figure 7 Stress and strain cloud diagram of sprayer frame in typical working conditions

\subsection{Chassis performance analysis}

\subsubsection{Stability performance analysis}

Due to the high quality, high ground clearance, and the complex road conditions encountered by the sprayer, it is necessary to comprehensively analyze its longitudinal stability and lateral stability to evaluate the sprayer's operating stability. When the sprayer was running at a constant speed or was stopped on a slope, the ultimate longitudinal angle and the lateral tumbling angle were selected to evaluate the machine's stability. As shown in Figure 8, the sprayer was assumed to run slowly at a constant speed on the ramp; the air resistance was not considered and the tire was treated as a rigid body. The moments of the $O_{2}, O_{1}$, and $O_{\mathrm{L}}$ points were determined, and the moment balance equations (Equations (1)-(3)) were established. In the equations, $\theta_{\lim }^{\prime}$ represents the angle of the tipping point when the chassis is driven downhill longitudinally $\left(^{\circ}\right)$.

$$
\begin{gathered}
h G \sin \theta_{\lim }+F_{\mathrm{z} 1} L=(L-a) G \cos \theta_{\lim } \\
h G \sin \theta_{\lim }^{\prime}+F_{\mathrm{z} 1} L=a G \cos \theta_{\lim }^{\prime} \\
h G \sin \theta_{\mathrm{lim}}+F_{\mathrm{z} 1} B=0.5 B G \cos \varphi_{\lim }
\end{gathered}
$$

When the sprayer was climbing a slope and the front wheel of the chassis was not affected by the normal force of the soil, it was considered to be in the critical state of the upward slope limit. At this time, both $F_{\mathrm{z} 1}$ and $F_{\mathrm{q} 1}$ were zero. $\theta_{\lim }$ was be obtained by including $F_{\mathrm{z} 1}$ and $F_{\mathrm{q} 1}$ into Equation (1).

$$
\theta_{\lim }=\arctan \frac{L-a}{h}
$$

Similarly, $\theta_{\lim }^{\prime}$ and $\varphi_{\lim }$ were obtained using Equations (2) and (3). 


$$
\begin{aligned}
\theta_{\text {lim }}^{\prime} & =\arctan \frac{a}{h} \\
\varphi_{\text {lim }} & =\arctan \frac{B}{2 h}
\end{aligned}
$$

Equations (4) to (6) indicate that the sprayer chassis stability was closely related to the barycenter position. Due to the large mass of the sprayer's pesticide tank and spray boom, the barycenter position of the sprayer will change under different loads and working conditions. We used Creo Parametric 2.0 software to analyze the axial weight ratio and barycenter position of the sprayer under various working conditions and found that during transport with full load and narrow wheel track $(B=3200 \mathrm{~mm})$, the spray boom was tucked. At this time, the sprayer barycenter position was higher and the weight ratio between the front and rear axle was high and the sprayer stability was poor. The weight ratio between the front and rear axle under this condition was 0.675:0.325, $a=1300 \mathrm{~mm}$, and $h=2256 \mathrm{~mm}$. These parameters were used in Equations (4)-(6) to obtain $\theta_{\lim }=50.1^{\circ}, \theta_{\lim }^{\prime}=30.0^{\circ}$, and $\varphi_{\lim }=35.3^{\circ}$. Under these conditions, the designed sprayer had good stability.

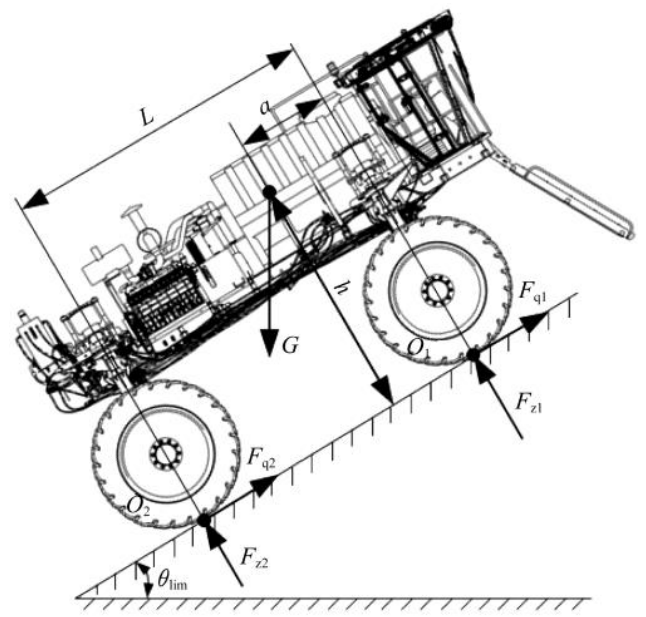

a. Driving along the ramp

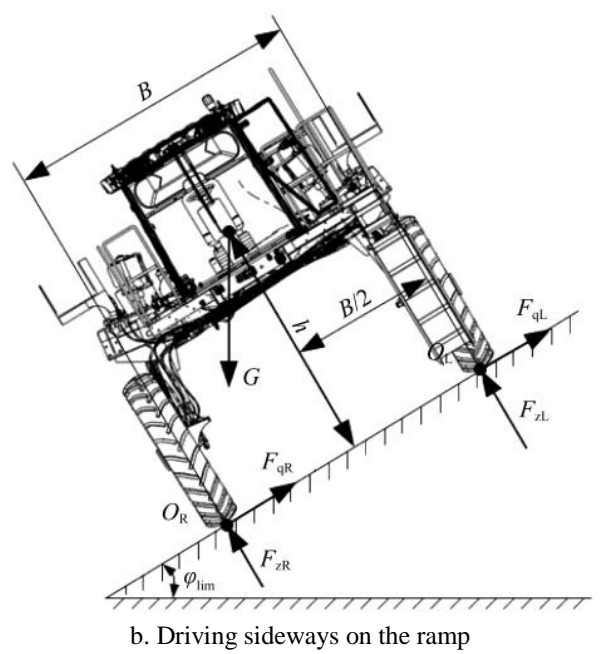

Note: $L$ is the wheel tread, $\mathrm{mm} ; B$ is the wheelbase, $\mathrm{mm} ; a$ is front axle to center of gravity distance, $\mathrm{mm} ; h$ is center of gravity to the vertical height of the ground, $\mathrm{mm} ; O_{1}, O_{2}, O_{\mathrm{L}}, O_{\mathrm{R}}$ are the contact points of the front wheel, rear wheel, left wheel, right wheel and ground of the chassis, respectively; $G$ is sprayer weight, $\mathrm{N} ; F_{\mathrm{z} 1}, F_{\mathrm{z} 2}, F_{\mathrm{zL}}, F_{\mathrm{zR}}$ are the normal forces of the soil on the front, rear, left, and right wheels, respectively, $\mathrm{N} ; F_{\mathrm{qL}}, F_{\mathrm{qR}}$ are the lateral forces of the soil on the left and right wheels, respectively, $\mathrm{N} ; \theta_{\lim }$ is the limit tumbling angle when the chassis is uphill, $\left({ }^{\circ}\right) ; \varphi_{\lim }$ is the limit tumbling angle of the chassis when driving laterally on the ramp, $\left(^{\circ}\right)$.

Figure 8 Analysis of vertical and lateral limit tipping state of sprayer chassis

\subsubsection{Four-wheel steering performance analysis}

The large high-clearance sprayer used four-wheel hydraulic steering. When the sprayer was turning, the steering gear controlled the extension and shortening of the hydraulic cylinder on each suspension by controlling the direction and amount of hydraulic oil flow and drove the four tires simultaneously to achieve the required turning radius. The vehicle steering performance was evaluated by determining the minimum turning radius $r_{\mathrm{zmin}}$ and turning width $B_{\mathrm{k}}$. Figure 9 shows a schematic view of the sprayer chassis with four wheels smoothly turning.

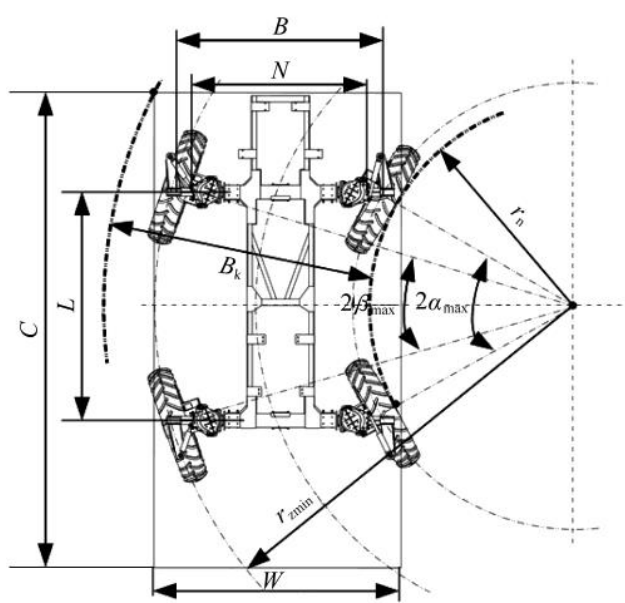

Note: $N$ is the distance between the center line of the left and right vertical axis and the ground intersection, $\mathrm{mm} ; C$ is the length of the whole machine, $\mathrm{mm} ; W$ is the width of the whole machine, $\mathrm{mm} ; B_{\mathrm{k}}$ is the turning width, $\mathrm{mm} ; \alpha_{\max }, \beta_{\max }$ are the maximum deflection angles of the inner and outer wheels, respectively, $\left(^{\circ}\right)$; $r_{\mathrm{zmin}}$ is the minimum turning radius, $\mathrm{mm} ; r_{\mathrm{n}}$ is the inner wheel turning circle radius, $\mathrm{mm}$.

Figure 9 Four-wheel steering schematic of sprayer chassis

The values of $r_{\mathrm{zmin}}$ and $r_{\mathrm{n}}$ were obtained by referring to [33,34], as shown in Equations (7) and (8).

$$
\begin{gathered}
r_{\mathrm{z} \text { min }}=\sqrt{\left[\left(\frac{L}{2}\right)^{2}+\left(\frac{L \cot \alpha_{\max }}{2}+N\right)^{2}\right]}+\frac{B-N}{2} \\
r_{\mathrm{n}}=r_{\mathrm{z} \min }-B+\frac{b}{2}
\end{gathered}
$$

where, $b$ is the tire width, mm. $\quad B_{\mathrm{k}}$ was calculated based on $r_{\mathrm{zmin}}$ and $r_{n}$, as shown in Equation (9).

$$
B_{\mathrm{k}}=\sqrt{r_{\mathrm{z} \min }^{2}+\frac{C^{2}}{4}}-r_{\mathrm{n}}
$$

According to the Ackerman steering principle, during four-wheel steering, there is an ideal angular relationship between the outer wheel and inner wheel, as defined in Equation (10).

$$
\beta=\operatorname{arccot}\left(\frac{2 N}{L}+\cot \alpha\right)
$$

The wheelbase $L$ was $4000 \mathrm{~mm}$, the wheel track B ranged from 3200 to $4000 \mathrm{~mm}$, the length $\mathrm{C}$ was $7495 \mathrm{~mm}$, the width $W$ was $4380 \mathrm{~mm}$, and $N$ ranged from 2140 to $2940 \mathrm{~mm}$. The maximum deflection angle $\alpha_{\max }$ of the inner front wheel was $36^{\circ}$. When $N$ was $2140 \mathrm{~mm}, 2340 \mathrm{~mm}, 2540 \mathrm{~mm}, 2740 \mathrm{~mm}$, and $2940 \mathrm{~mm}$, the minimum turning radius $r_{\text {zmin }}$ was $5816 \mathrm{~mm}, 6001 \mathrm{~mm}, 6188 \mathrm{~mm}$, $6376 \mathrm{~mm}$, and $6564 \mathrm{~mm}$, respectively as determined by Equations (7)-(10), the turning width $B_{\mathrm{k}}$ was $4113 \mathrm{~mm}, 4283 \mathrm{~mm}, 4456 \mathrm{~mm}$, $4630 \mathrm{~mm}$, and $4804 \mathrm{~mm}$ and the maximum angle $\beta_{\max }$ of the outer wheel was $30.49^{\circ}, 29.08^{\circ}, 27.78^{\circ}, 26.58^{\circ}$, and $25.48^{\circ}$ respectively. These values satisfied the field management requirements of the sprayer in large plots. 


\subsubsection{Obstacle crossing performance analysis}

The sprayer occasionally has to cross field obstacles. The ability to cross obstacles was evaluated to determine the sprayer chassis handling performance. During obstacle crossing, the sprayer drove at a low speed, which represents a static problem. Figure 10 shows the forces acting on the sprayer chassis during obstacle crossing.

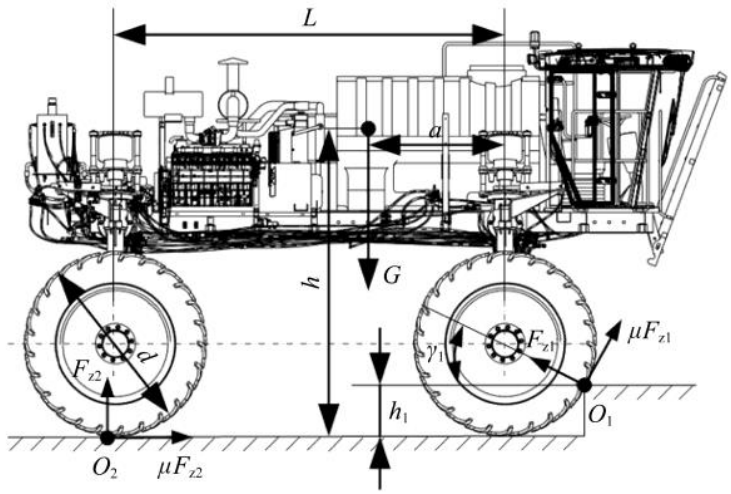

a. Front wheel cross the obstacle

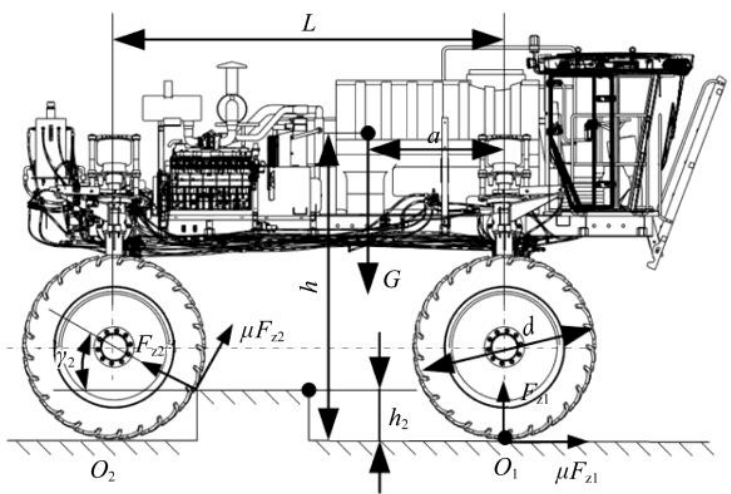

b. Rear wheel cross the obstacle

Note: $\mu$ is the soil adhesion coefficient; $h_{1}, h_{2}$ are the height of the obstacle crossed by the front and rear wheels, respectively, $\mathrm{mm} ; \gamma_{1}, \gamma_{2}$ are the angles between the normal force of the front and rear wheels and the horizontal plane, respectively $\left({ }^{\circ}\right)$.

Figure 10 Force analysis of the sprayer chassis through obstacles

The tire deformation was ignored and obstacle crossing began when the front wheel center point touched the obstacle according to the geometric relationship shown in Figure 10a. Equation (11) is the balance equation for the front wheel crossing the obstacle.

$$
\left\{\begin{array}{l}
F_{\mathrm{z} 2} L=\frac{\mu F_{\mathrm{z} 1} d}{2}+\frac{\mu F_{\mathrm{z} 2} d}{2}+G a \\
G=F_{\mathrm{z} 1} \sin \gamma_{1}+\mu F_{\mathrm{z} 1} \cos \gamma_{1}+F_{\mathrm{z} 2} \\
F_{\mathrm{z} 1} \cos \gamma_{1}=\mu F_{\mathrm{z} 1} \sin \gamma_{1}+\mu F_{\mathrm{z} 2} \\
\sin \gamma_{1}=1-\frac{2 h_{1}}{d}
\end{array}\right.
$$

By simplifying Equation (11), the obstacle crossing height of the front wheel was obtained, as shown in Equation (12).

$$
\left\{\begin{array}{l}
h_{1}=\frac{d}{2}\left(1+\frac{\lambda \tau}{\tau^{2}+\delta^{2}}-\sqrt{\frac{\lambda^{2} \tau^{2}}{\left(\tau^{2}+\delta^{2}\right)^{2}}-\frac{\lambda^{2}-\delta^{2}}{\tau^{2}+\delta^{2}}}\right) \\
\delta=\frac{1}{\mu}-\frac{d}{2 L}-\frac{a}{\mu L}-\frac{a \mu}{L}, \lambda=\frac{d \mu}{2 L}, \tau=\frac{1}{\mu}-\frac{d}{2 L}
\end{array}\right.
$$

Similarly, as shown in the geometric relationship in Figure 10b, the obstacle crossing height of the rear wheel was obtained using Equation (13).

$$
\left\{\begin{array}{l}
h_{2}=\frac{d}{2}\left(1-\frac{\lambda_{1} \tau_{1}}{\tau_{1}^{2}+\delta_{1}^{2}}-\sqrt{\frac{\lambda_{1}^{2} \tau_{1}^{2}}{\left(\tau_{1}^{2}+\delta_{1}^{2}\right)^{2}}-\frac{\lambda_{1}^{2}-\delta_{1}^{2}}{\tau_{1}^{2}+\delta_{1}^{2}}}\right) \\
\delta_{1}=\frac{d}{2 L}-\mu+\frac{a}{\mu L}+\frac{a \mu}{L}, \lambda_{1}=\frac{d \mu}{2 L}, \tau_{1}=1+\frac{d \mu}{2 L}
\end{array}\right.
$$

According to Equations (12) and (13), the obstacle crossing ability of the front and rear wheels is independent of the barycenter height, but is closely related to the distance from the barycenter to the front axis $a$ and the diameter of the wheel travel diameter $d$. When the sprayer was fully loaded and the spray boom was closed, $\mu$ was set at 0.45 and the obstacle crossing height of the front and rear wheels were $466 \mathrm{~mm}$ and $457 \mathrm{~mm}$ respectively. The obstacle crossing ability of the front wheel decreased with the decrease of $a$ value, whereas that of the rear wheel increased with the decrease of $a$ value. The sprayer designed in this paper adopts the layout order of cab $\rightarrow$ pesticide tank $\rightarrow$ engine $\rightarrow$ spray boom, which can move the sprayer barycenter forward and reduce the value of $a$, so that the front and rear wheel obstacle crossing ability remained consistent.

In order to prove the correctness of the chassis performance analysis, Creo Parametric 2.0 was used to establish sprayer 3D model, as shown in Figure 11. Sprayer kinematic analysis was performed using the mechanism analysis module of Creo software. The sprayer's stability, steering, and obstacle crossing ability obtained from the kinematics analysis were basically consistent with the results of the chassis performance analysis.
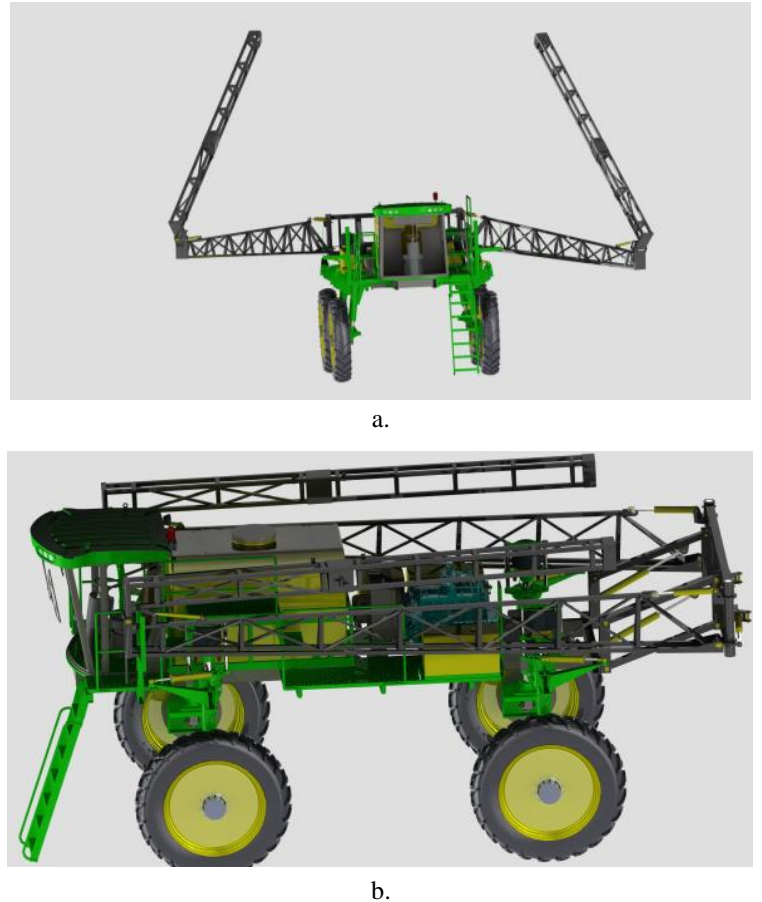

Figure 11 Sprayer 3D model established by Creo Parametric 2.0

\section{Results and discussion}

In order to verify the validity of the analysis, from December 2017 to August 2018, the sprayer chassis designed in this study was tested with full load at the test base of Shandong Wuzheng Agricultural Equipment Co., Ltd., Rizhao City, Shandong Province. The hydraulic oil tank, fuel tank and pesticide tank of the sprayer had been filled. The experiment followed the standards, such as GB/T24677.2-2009 "Boom sprayer-Test methods", GB/T5667-2008 "Productive testing methods for agricultural machinery", and Agricultural Machinery Promotion and Appraisal 
Outline DG/T010-2011 "Boom Sprayer" to test the performance of the sprayer chassis. The tools used in the experiment included a tape measure (range $0-10 \mathrm{~m}$, accuracy $\pm 1 \mathrm{~mm}$ ), a steel ruler (range 0-500 $\mathrm{mm}$, accuracy $\pm 1 \mathrm{~mm}$ ), an angle measuring instrument (range $0^{\circ}-180^{\circ}$, accuracy $\pm 0.1^{\circ}$ ), a Milang MPS-XS draw-wire displacement sensor (range 0-500 mm, sensitivity $10 \mathrm{mv} / \mathrm{mm}$, accuracy $0.3 \%$ FS), and a 356A15 accelerometer (PCB Co., USA) (range: $\pm 50 \mathrm{~g}$, sensitivity $100 \mathrm{mv} / \mathrm{g}$, accuracy $0.0002 \mathrm{~g}$ ). The displacement sensor and acceleration sensor data were acquired using a NI USB-6341 data acquisition card, LabVIEW software, and a CoCo80X dynamic signal acquisition instrument. The experimental process is outlined in Figure 12.

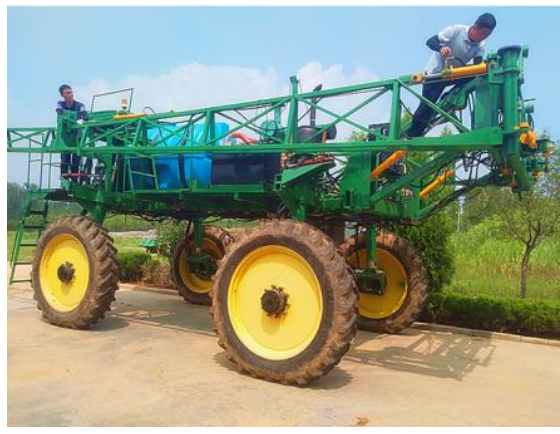

a. Experimental prototype

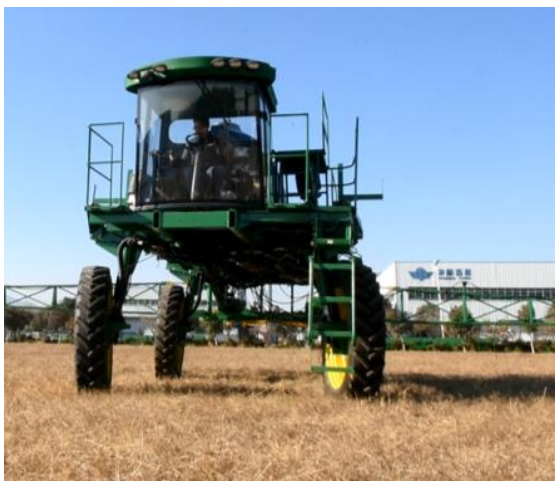

b. Steering Experiment

Figure 12 Performance experiment of sprayer chassis

The sprayer drive system was tested, and the sprayer highest speeds in 1st, 2nd, 3rd, and 4th gears were about $15 \mathrm{~km} / \mathrm{h}, 21 \mathrm{~km} / \mathrm{h}$, $25 \mathrm{~km} / \mathrm{h}$, and $38 \mathrm{~km} / \mathrm{h}$, respectively. At this time, the corresponding steady-state pressures of the hydrostatic drive system were 6.361 MPa, 7.286 MPa, 8.717 MPa, and 10.343 MPa, respectively. The sprayer running speed and the hydrostatic drive system steady-state pressure showed that the designed drive system could meet the requirements of sprayer different operating conditions, and the drive system had fast dynamic response and good performance. The performance indices of the sprayer chassis' climbing angle, turning radius, obstacle crossing height, and wheel track adjustment were evaluated three times. The results of each experiment were processed and averaged. The experimental results are shown in Table 2. The results indicated that the sprayer chassis successfully navigated an obstacle with a height of $400 \mathrm{~mm}$ and the chassis remained stable when the longitudinal slope and the lateral slope were $25^{\circ}$. These results demonstrated that the sprayer met the crop plant protection requirements of large plots. Due to machining errors, the sprayer's clearance height and wheel track were larger than the design value. The minimum turning radius and minimum turning width were larger than the theoretical values; the discrepancy was caused by a difference in the angle between the rear wheel and the front wheel during four-wheel hydraulic steering; however, the experimental results met the design requirements.

Table 2 Results of experiment during sprayer transport condition with full load

\begin{tabular}{|c|c|c|c|}
\hline Performance & Experiment results & Analysis results & Design requirements \\
\hline Full load/kg & 12447 & 12000 & 12000 \\
\hline $\begin{array}{l}\text { Boundary } \\
\text { dimension/mm }\end{array}$ & $7574 \times 4534 \times 4598$ & $7500 \times 4500 \times 4500$ & $7500 \times 4500 \times 4500$ \\
\hline $\begin{array}{l}\text { Obstacle crossing } \\
\text { height } / \mathrm{mm}\end{array}$ & 400 & $\begin{array}{l}\text { Front wheel: } 466 \\
\text { Rear wheel: } 457\end{array}$ & $\geq 300$ \\
\hline Climbing angle $/\left(^{\circ}\right)$ & 25 & 50.1 & $\geq 20$ \\
\hline Roll angle $/\left({ }^{\circ}\right)$ & 25 & 35.3 & $\geq 20$ \\
\hline $\begin{array}{l}\text { Minimum turning } \\
\text { radius } / \mathrm{mm}\end{array}$ & 5916 & 5816 & $\leq 6500$ \\
\hline $\begin{array}{l}\text { Minimum turning } \\
\text { width } / \mathrm{mm}\end{array}$ & 4232 & 4113 & $\leq 5000$ \\
\hline $\begin{array}{l}\text { Clearance height } \\
/ \mathrm{mm}\end{array}$ & 2050 & 2000 & $\geq 2000$ \\
\hline Wheel track/mm & $\begin{array}{l}\text { Maximum: 4056; } \\
\text { minimum: } 3234\end{array}$ & $\begin{array}{l}\text { Maximum: } 4000 \text {; } \\
\text { minimum: } 3200\end{array}$ & $\begin{array}{l}\text { Maximum: } 4000 ; \\
\text { minimum: } 3200\end{array}$ \\
\hline
\end{tabular}

In order to verify the vibration damping performance of the designed sprayer chassis suspension, a sprayer chassis vibration test platform was constructed, as shown in Figure 13. The draw wire displacement sensor was used to measure the suspension's dynamic deflection. The acceleration sensors were used to measure the sprung mass acceleration and unsprung mass acceleration of the suspension. During the experiment, the sampling frequency was $100 \mathrm{~Hz}$ and the sprayer chassis covered typical road conditions at a uniform speed of $12 \mathrm{~km} / \mathrm{h}$ (general sprayer operating speed); the signal data collected by the displacement sensors and acceleration sensors were recorded.

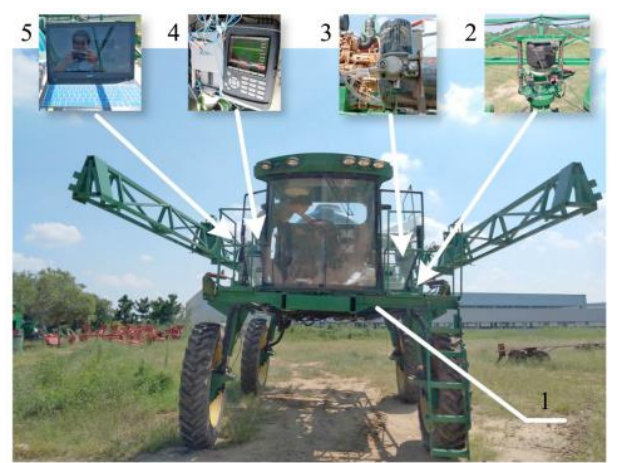

1. Test platform 2. Suspension test system (including pull-line displacement sensor, acceleration sensor, etc.) 3. Air source system (including air reservoir air dryer, solenoid valve, etc.) 4. Measurement and control system (including acquisition card, dynamic signal acquisition instrument) 5. Storage system (including computer, power supply, etc.)

Figure 13 Performance experiment of sprayer chassis suspension

Figure 14a shows the time-domain acceleration signals of the sprung mass and unsprung mass of the left front air suspension. Figure 14(b) shows the time-domain signals of the left front air suspension's dynamic deflection. The root mean square (RMS) values of the sprung mass and unsprung mass acceleration were $2.054 \mathrm{~m} / \mathrm{s}^{2}$ and $15.234 \mathrm{~m} / \mathrm{s}^{2}$, respectively. The RMS value of the suspension's dynamic deflection was $19.1 \mathrm{~mm}$, which was about $1 / 3$ less than that $(33.3 \mathrm{~mm})$ of the suspension limit stroke, indicating that the designed sprayer chassis suspension exhibited a good damping effect.

Table 3 shows the RMS values of the sprung and unsprung mass obtained from the sensors. The RMS values of the sprayer 
cab floor vertical acceleration and sprung mass acceleration of the springs were much smaller than those of the unsprung mass. The RMS values of the horizontal and longitudinal acceleration of the cab floor and those of the dynamic deflections of the springs were small, indicating that the designed sprayer chassis had good ride comfort. The RMS values were higher for the rear side suspensions than the front side suspensions; this was attributed to the additional vibration of the rear side suspensions when the engine was running.

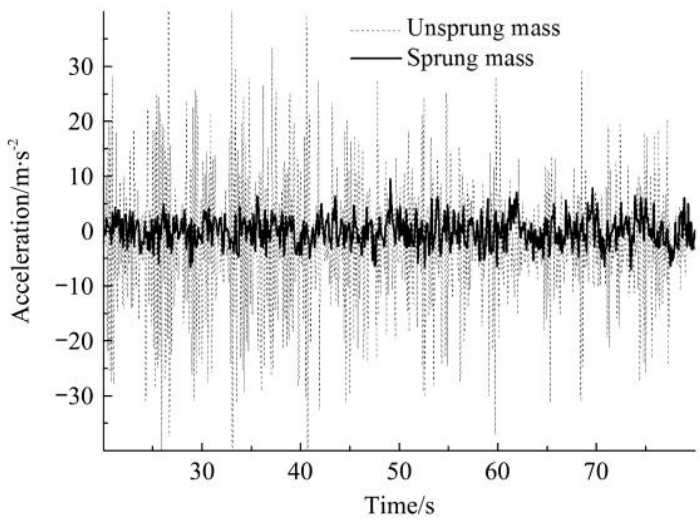

a. Acceleration

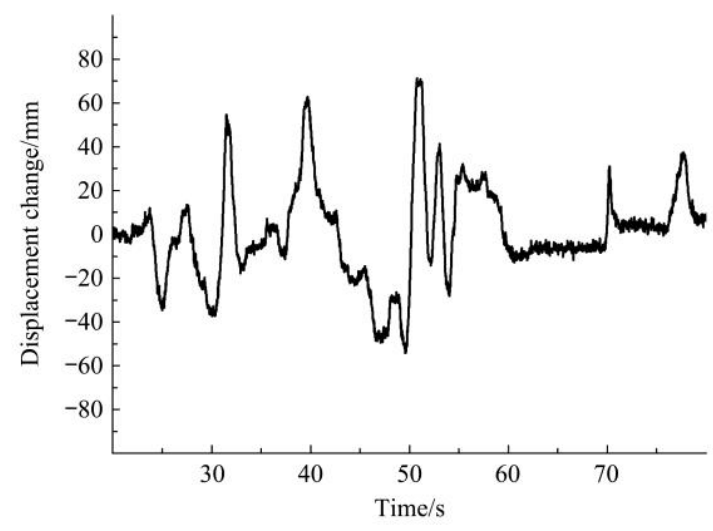

b. Displacement

Figure 14 Experiment results of left front air suspension

Table 3 Root mean square experiment results of each sensor

\begin{tabular}{lcc}
\hline \multirow{2}{*}{ Sensor position } & \multicolumn{2}{c}{ Values of RMS } \\
\cline { 2 - 3 } & Acceleration $/ \mathrm{m} \cdot \mathrm{s}^{-2}$ & Dynamic deflection $/ \mathrm{mm}$ \\
\hline Top of left front spring & 2.054 & 19.1 \\
Bottom of left front spring & 15.234 & 20.3 \\
\hline Top of right front spring & 1.956 & 22.0 \\
Bottom of right front spring & 13.476 & 22.8 \\
\hline Top of left rear spring & 2.934 & $/$ \\
Bottom of left rear spring & 16.333 & $/$ \\
\hline Top of right rear spring & 2.889 & $/$ \\
Bottom of right rear spring & 16.172 & \\
\hline Horizontal & 0.563 & \\
Cab floor $\quad$ Longitudinal & 0.487 & \\
\hline
\end{tabular}

\section{Conclusions}

A large high-clearance self-propelled sprayer chassis was designed according to the sprayer's driving requirements and the overall goal and the structural characteristics and working principle of the chassis drive system, suspension system, track adjustment system, and frame were analyzed.
(1) The sprayer frame was designed, and A finite element analysis of the frame was carried out under four extreme conditions: full load bending, full load torsion, full load emergency braking and full load emergency turning. Under these four conditions, the maximum stress values of the frame were $149.45 \mathrm{MPa}, 219 \mathrm{MPa}$, 151.44 $\mathrm{MPa}$, and 123.27 $\mathrm{MPa}$ respectively, and the maximum strain values were $1.12 \mathrm{~mm}, 2.22 \mathrm{~mm}, 0.95 \mathrm{~mm}$, and $1.16 \mathrm{~mm}$ respectively. According to the static analysis results of various working conditions, the overall stiffness and strength of the frame were good, which provided an evidence for frame dynamic analysis and structure optimization.

(2) A theoretical analysis of the stability, steering ability, and obstacle navigation of the sprayer chassis was conducted. The results analysis showed that the upper angle $\theta_{\text {lim }}$, lower angle $\theta_{\text {lim }}^{\prime}$, and lateral limit tumbling angle $\varphi_{\lim }$ of the sprayer chassis were $50.1^{\circ}, 30.0^{\circ}$, and $35.3^{\circ}$ respectively. The minimum turning radius of the chassis for different wheel track settings were $5816 \mathrm{~mm}$, $6001 \mathrm{~mm}, 6188 \mathrm{~mm}, 6376 \mathrm{~mm}$, and $6564 \mathrm{~mm}$. The turning widths for different wheel track settings were $4113 \mathrm{~mm}, 4283 \mathrm{~mm}$, $4456 \mathrm{~mm}, 4630 \mathrm{~mm}$, and $4804 \mathrm{~mm}$. The theoretical maximum angles of the chassis outer wheel for different wheel treads were $30.49^{\circ}, 29.08^{\circ}, 27.78^{\circ}, 26.58^{\circ}$, and $25.48^{\circ}$. The maximum obstacle crossing heights of the front and rear wheels were $466 \mathrm{~mm}$ and $457 \mathrm{~mm}$, respectively. The theoretical analysis showed that the designed chassis met the field management operations of large plots.

(3) Field experiments of the large-scale high-clearance self-propelled sprayer chassis were conducted. The results showed that the designed chassis remained stable on a longitudinal and lateral slope of $25^{\circ}$ and was able to cross a height of $400 \mathrm{~mm}$; the minimum turning radius and turning width during the experiment were $5916 \mathrm{~mm}$ and $4232 \mathrm{~mm}$. The RMS values of the sprayer cab floor vertical acceleration and sprung mass acceleration of the springs were much smaller than those of the unsprung mass. The RMS values of the horizontal and longitudinal acceleration of the cab floor were also small and the deflections of the springs were $1 / 3$ smaller than those $(33.3 \mathrm{~mm})$ of the suspension limit stroke, indicating that the designed chassis suspension had a good damping effect.

\section{Acknowledgements}

The authors acknowledge that this work was financially supported by the Key Research and Development Program of Shaanxi Province (No. 2019ZDLNY02-01) and the China Postdoctoral Science Foundation (No. 2018M643744). The authors also thank the editing team of EditorBar for improving the English language fluency of the paper.

\section{[References]}

[1] Wang Z C, He X K, Li T, Huang M Y, Zhang Y P, Xu L, et al Evaluation method of pesticide droplet drift based on laser imaging. Transactions of the CSAE, 2019; 35(9): 73-79. (in Chinese)

[2] Gil E, Gallart M, Balsari P, Marucco P, Almajano M P, Llop J. Influence of wind velocity and wind direction on measurements of spray drift potential of boom sprayers using drift test bench. Agricultural and forest Meteorology, 2015; 202: 94-101.

[3] Julián S, Víctor J R, Francisco P, Francisco A, Carvajal F. Field evaluation of a self-propelled sprayer and effects of the application rate on spray deposition and losses to the ground in greenhouse tomato crops. Pest Management Science, 2011; 67(8): 942-947.

[4] Zhuang T F, Yang X J, Dong X, Zhang T, Yan H R, Sun X. Research status and development trend of large self-propelled sprayer booms. 
Transactions of the Chinese Society for Agricultural Machinery, 2018; 49(S1): 196-205. (in Chinese)

[5] Jeon H Y, Womac A R, Gunn J. Sprayer boom dynamic effects on application uniformity. Transactions of the ASAE, 2004; 47(3): 647-658.

[6] Peters M D, Heinen P J, Venton-Walters R, Klemp Jr G J. Agricultural spray boom. U.S. Patent 9848592, 2017-12-26.

[7] Luck J D, Sharda A, Pitla S K, Fulton J P, Shearer S A. A case study concerning the effects of controller response and turning movements on application rate uniformity with a self-propelled sprayer. Transactions of the ASABE, 2011; 54(2): 423-431.

[8] Cui L F, Xue X Y, Ding S M, Gu W, Chen C, Le F X. Modeling and simulation of dynamic behavior of large spray boom with active and passive pendulum suspension. Transactions of the CSAM, 2017; 48(2): 82-90. (in Chinese)

[9] Cui L F, Xue X Y, Ding S M, Qiao B Y, Le F X. Analysis and test of dynamic characteristics of large spraying boom and pendulum suspension damping system. Transactions of the CSAE, 2017; 33(9): 61-68. (in Chinese)

[10] Tahmasebi M, Mailah M, Gohari M, Abd R R. Vibration suppression of sprayer boom structure using active torque control and iterative learning, part i: modelling and control via simulation. Journal of Vibration and Control, 2018; 24(20): 4689-4699.

[11] Tahmasebi M, Gohari M, Mailah M, Abd R R. Vibration suppression of sprayer boom structure using active torque control and iterative learning, part ii: experimental implementation. Journal of Vibration and Control, 2018; 24(20): 4740-4750.

[12] Xue T, Li W, Du Y F, Mao E R, Wen H J. Adaptive fuzzy sliding mode control of spray boom active suspension for large high-clearance sprayer. Transactions of the CSAE, 2018; 34(21): 47-56. (in Chinese)

[13] Parloo E, Guillaume P, Anthonis J, Heylen W, Swevers J. Modelling of sprayer boom dynamics by means of maximum likelihood identification techniques, Part 1: A comparison of input-output and output-only modal testing. Biosystems Engineering, 2003; 85(2): 163-171.

[14] Parloo E, Guillaume P, Anthonis J, Heylen W, Swevers J. Modelling of sprayer boom dynamics by means of maximum likelihood identification techniques, Part 2: Sensitivity-based mode shape normalization, Biosystems Engineering, 2003; 85(3): 291-298.

[15] Wei X H, Shao J, Miao D D, Li L, Xie X W. Online control system of spray boom height and balance. Transactions of the Chinese Society for Agricultural Machinery, 2015; 46(8): 66-71. (in Chinese)

[16] Garcia-Ramos F J, Vidal M, Boné A, Serreta A. Methodology for the regulation of boom sprayers operating in circular trajectories. Sensors, 2011; 11(4): 4295-4311.

[17] Karale D S, Kankal U S, Khambalkar V P, Gajakos A V. Performance evaluation of self-propelled boom sprayer. International Journal of Agricultural Engineering, 2014; 7(1): 137-141.

[18] Gao Q, Gao F, Tian L, Li L, Ding N, Xu G, et al. Design and development of a variable ground clearance, variable wheel track self-leveling hillside vehicle power chassis (V2-HVPC). Journal of Terramechanics, 2014; 56: 77-90.

[19] Mao H P, Ni J, Han L H, Zuo Z Y, Gu J, Zhang X D. Turning anti-slip control system of hydraulic four-wheel drive high clearance sprayer. Transactions of the CSAM, 2012; 43(6): 66-71. (in Chinese)

[20] Chen S Y, Du Y F, Xie B, Song Z H, Mao E R, Chen Y. Design and performance analysis of drive system for high clearance self-propelled corn detasseling machine. Transactions of the CSAE, 2016; 32(22): 10-17. (in Chinese)

[21] Han H Y, Chen S R, Shao J S, Yao Y, Chen G. Lightweight design of chassis frame for motor boom sprayer. Transactions of the CSAE, 2013; 29(3): 47-53+293. (in Chinese)

[22] Chen S R, Han Y H, Chen G, Shao J S, Yao Y. Dynamic characteristic analysis and vibration reduction design for sprayer frame. Transactions of the CSAM, 2013; 44(4): 50-53. (in Chinese)

[23] Yang F F, Yan G, Hao Y X, Liu K G. Study on the characteristics of steering system for high clearance sprayer based on rigid-flexible coupling simulation model. Journal of Jilin University (Engineering and Technology Edition), 2015; 45(3): 857-863. (in Chinese)

[24] Li Wei, Xue T, Mao E R, Du Y F, Li Z, He X K. Design and experiment of multifunctional steering system for high clearance self-propelled sprayer Transactions of the Chinese Society for Agricultural Machinery, 2019; 50(1): 141-151. (in Chinese)

[25] Wu X H, Qin J H, Du Y F, Song Z H, Chen Y, Xie B. Experiments of vibration control for active pneumatic suspension system in high clearance self-propelled sprayer. Transactions of the Chinese Society for Agricultural Machinery, 2018; 49(6): 60-67. (in Chinese)

[26] Li W, Chen Y, Zhang S, Mao E R, Du Y F, Wen H J. Damping characteristic analysis and experiment of air suspension with auxiliary chamber. IFAC-PapersOnLine, 2018; 51(17): 166-172.

[27] Chen L Q, Wang P P, Zhang P, Zheng Q, He J, Wang Q J. Performance analysis and test of a maize inter-row self-propelled thermal fogger chassis. Int J Agric \& Biol Eng, 2018; 11(5): 100-107.

[28] Song S J, Li Y, Qu J W, Zhou W, Guo K Q. Design and test of flexible chassis automatic tracking steering system. Int J Agric \& Biol Eng, 2017; 10(5): 45-54.

[29] Chen Y, Zhang S, Mao E R, Du Y F, Chen J, Yang S J. Height stability control of a large sprayer body based on air suspension using the sliding mode approach, Information Processing in Agriculture, 2019. doi: https://doi.org/10.1016/j.inpa.2019.06.003.

[30] Chen Y, Chen S Y, Du Y F, Zhu Z X, Mao E R, Fu Q F. Damping characteristics of chassis suspension system of high clearance agricultural machinery based on friction damper. Transactions of the CSAE, 2016; 34(7): 51-57. (in Chinese)

[31] Zatrieb J, Kasler R. New generation of hydro-pneumatic suspension systems with adaptive damping, SAE Technical Paper, 2012.

[32] Čedík J, PražAn R. Comparison of tyres for self-propelled sprayers. Agronomy Research, 2015; 13(1): 53-62.

[33] Wang J W, Tang H, Shen H G, Bai H C, Na M J. Design and experiment of high-clearance roll-waist multifunctional power chassis for paddy field. Transactions of the CSAE, 2017; 33(16): 32-40. (in Chinese)

[34] Hao C H, Yang X J, Liu L J, Yin S Z, Liu S P, Zhao J H. Design and experiment of multifunctional dynamic chassis for orchard. Transactions of the CSAM, 2018; 49(12): 66-73, 92. (in Chinese) 